\title{
Ugly truth of bigotry and prejudice
}

\section{Opinion}

Nobody talks about it out loud. It's like a dirty little secret, but everybody knows. Whispers in the hallway. Gossip around the water cooler. She has blonde hair and bright, crystal blue eyes. Her clothing is perfect. She got straight A's in school. Everyone tells her what a beautiful smile she has. But there's something different about her. People move to avoid touching her. Even the kindergartner on the playground will sit next to the hairy old veteran with one leg missing before sitting next to her. She's the F word.

She goes about her business from day to day. She works in the hospitality industry on the evening shift. People call her with all sorts of questions and requests - some that are way off the wall. She tells them she can handle it and she does. They compliment her all the time. "You really made my stay special!" "No one cares like you do!" Then they see her in person and the compliments dry up. They wanted to hug her on the phone and now they just won't. She's the F word.

Did you figure it out yet? This intelligent, classy, helpful woman has an Unhealthy Weight. They call her - Fat.

Our society has endorsed a lot of prejudice over the years with words that now make us cringe. Nig..., Spi..., Wetb..., Quee..., among others. The government has made it illegal to discriminate on the basis of creed, color, religion, even national origin. What discrimination is still legal in all 50 states? Obesity.

People with an unhealthy weight are considered by many to be lazy, unmotivated, weak-willed, and over indulgent. In fact, some think they are less intelligent and less attractive. Mostly they are thought of as Unsuccessful.

Guess what? 7 out of 10 of you are Fat. So let's get past the name calling.

When our older doctors were still in school, we didn't know much about fat. Even during the days of PhenFen, we thought fat only protected you from injury and kept you warm at night. In the past 25years, though, science had uncovered the fact that fat cells are the most metabolically active cells in your body and put out over 100 different hormones. Only 2 have any benefit - Adiponectin, and Leptin - and they are weak at best. The rest - like interleukins and cytokines - are causes of inflammation and pain. These cause a lot of the chronic
Volume 6 Issue I - 2017

\author{
Brent Gear \\ Board certified in emergency medicine and obesity, USA
}

Correspondence: Brent Gear DO, FACEP, FACOEP, FOMA, Board certified in emergency medicine and obesity (medical bariatrics), USA, Tel 602320856I,

Email brent@scoutpack324.com

Received: September 28, 2016 | Published: January 03, 2017

pain syndromes and may be the cause of Fibromyalgia and Chronic Fatigue Syndrome.

The girl in our story is real. She has lost 80 pounds in the past 6 months. She's still overweight, but according to the electronic body composition machine, she lost all fat and even gained a couple pounds of muscle. Her pain level is down to a "1". Her fatigue level is down to a "1". Her stress level? Well, she still has to deal with lots of requests and complaints at work, but she does not get the stares or uncomfortable silence or worse yet the snickers anymore. She has referred half a dozen people to a weight loss doctor and they have started a competition. She likes her life again.

Having "Fat" does not need define who you are. Some people feel they need to define themselves by their disease state: "I suffer from sugar diabetes". Just like Diabetes and Hypertension, Obesity is a chronic disease that gets better with treatment - and comes back without treatment. These are things that make up who you are, but guess what: you can do positive things with them.

Wanna know why you gained all that weight in the first place? Stay tuned!

\section{Acknowledgements}

None.

\section{Conflict of interest}

The author declares no conflict of interest. 